\title{
The influence of meaningfulness upon intentional and incidental learning of verbal material
}

\author{
STEPHEN WOLK \\ Lniversity of Maryland. College Park. Maryland 20742
}

\begin{abstract}
The present investigation concerned the relationship between intentional and incidental learning of verbal material. Both task meaningfulness (sequential dependency of the material) and shifts in performance over time were ex $\lrcorner$ mined for differential patterns under both types of learning conditions. Cover task performance consisted of the search for typographical errors across four paragraphs of a narrative, learning the recall and recognition of examples of categories of objects in the text. There was lack of support for the argument that incidental and intentional learning represent two distinct types; rather $S$ s responded similarly to increased task meaningfulness under both learning conditions and evidenced identical performance patterns over time. Results were interpreted within an intentional-attentional hypothesis of incidental learning.
\end{abstract}

The area of incidental learning remains a most differentiated collection of research. Both McLaughlin (1965) and Ryan (1970) present adequate overviews of the area and address themselves to general major issues that are of concern to the present study: (a) whether a continuity exists between intentional and incidental learning, implying nonqualitative differences between the two, or whether there are factors that are differentially involved in these phenomena and (b) identification of subject and task variables that best predict the level of incidental learning. The research surrounding incidental learning manifests certain weaknesses. several of which Kessler and Loyd (1970) have noted. Related to restricted tasks and tests of incidental learning, these reduce the generalizability of the findings. These include specifically: (a) reliance upon extremely controlled. discrete tasks of little relevance to more continuous, ongoing learning tasks: (b) use of narrowly defined measures of incidental learning (most often an immediate or short-term test of retention): and (c) employment of tasks that often artificially "isolate" the incidental material, relative to the intentional task, making it extremely extrinsic to the goals of the learner. (For example. learning of geometric forms. with the incidental material being the colors associated with these forms.)

While the Kessler and Loyd article can be faulted for some lack of control over stimulus presentation. reducing the validity of the results. it is clear that such methodological controls must be integrated within tasks that afford more generalizability. This was the general interest with which the specific questions of the present study were pursued.

Both the theory and research associated with incidental learning have considered level of meaningfulness as an important task parameter for such learning. Evidence of a differential effect upon intentional and incidental learning of meaningfulness would suggest qualitative differences between these types of learning. as well as the nature of any response differences the learner makes under varying levels of task meaningfulness. Suffice it to say, the literature has not afforded a clear answer to this issue. Kaswan (1957) used pairs of nonsense figures presented to incidental ("experiment concerned with ESP") and intentional ("memorize the figures in preparation for a recall test") groups. These pairs of figures were either categorized as fitting or nonfitting, primarily as a function of good continuation. Kaswan, while he does not report overall group means, does indicate that the mean difference between fitting and nonfitting pairs correctly recalled was 1.04 for the ESP group and .93 for the intentional group. This report suggests a lack of a differential effect of task meaningfulness upon intentional and incidental learning and. indeed, the beneficial effect of high task meaning upon incidental learning. Postman and Adams (1960). using verbal material and the manipulation of contextual relationships as an index of meaningfulness, argued that instructions to learn increase sensitivity to serial order; hence. sequential dependencies would be more beneficial, i.e., increase learning, under intentional as opposed to incidental conditions. Their data support this to some degree. contradicting the results of Kaswan. who used nonverbal material. as well as an earlier study by Postman. Adams, and Phillips (1955) in which the main difference between intentional and incidental conditions was for low-meaningful (nonsense syllables) material. Mechanic (1962) has essentially supported this finding.

It should be pointed out that. in regard to the task parameter of meaningfulness. only the Postman and Adams study (1960) used sequences of material as opposed to arbitrary syllable lists. The findings of this study of a differential effect of meaningfulness upon intentional and incidental learning are somewhat discrepant from the bulk of the research. The evaluation of this apparent discrepancy must await further experimentation in which sequences of material are used. Kessler and Loyd (1970) also used connected material (13-page article) and found no differences 
between an intentional and incidental group in regard to incidental material. However, the operations used to define the groups, as well as the controls. over the experimental procedure reduce the significance of these findings. For example, the authors simply instructed Ss to read the article at their convenience and placed no time restrictions on this reading. Additionally, the use of intact ongoing classes did not preclude a high degree of communication between the "intentional" and "incidental" Ss. Thus, the absence of differences between groups could be attributed to the failure of the author to exert more control over stimulus presentations and administration of experimental conditions.

The possibility of a differential effect of meaningfulness upon intentional-incidental learning relates most directly to the theoretical concern of the possible discontinuity between intentional and incidental learning. One dominant point of view is that intention is the manipulated variable in an intentional-incidental paradigm. and. thus, intention acts indirectly through its effects upon the attentional processes of the subject. While the nature of these attentional processes has been suggested (for example, cognitive prominence, organization, and arousal) but not fully delineated, this interpretation of incidental learning offers both the most parsimonious and powerful approach, as compared to rehearsal or differential responding. Those pursuing this attentional hypothesis have included Gleitman and Gillett (1957), Eagle and Leiter (1964), and Schneider and Kintz (1967). This hypothesis remains to be extended for data collected from a more continuous type of task.

Finally, data related to possible differential changes in intentional and incidental learning over time remain to be systematically collected. Given the discrete nature of most incidental tasks, such a question has been difficult to consider: however. within the context of a continuous interrelated task, the possibility of changing cognitive strategies for these types of learning, with increased familiarity or exposure to material, presents itself as a most compelling issue. It is in regard to the issues of task meaningfulness and related attentional shifts that the present paper considers intentional and incidental learning.

\section{METHOD}

\section{Subjects}

One hundred and thirty-six students from lower level graduate courses in educational psychology comprised the sample $(58$ males and 78 females).

\section{Materials}

An intentional-incidental learning task consisting of connected stimuli (textual material), the general format for several previous investigations (DuCette \& Wolk. 1973; Wolk \& DuCette, 1972), was employed. The material consisted of two separate stories: one concerning the discovery of a fictitious drug. the other the settlement of a nonexistent western town (both written by the E). Each story was composed of four paragraphs of seven sentences each. with approximately 200 words per paragraph.

\section{Procedure and Design}

The task was administered individually to insure experimental control over $\mathrm{Ss}^{\prime}$ responses. As a cover task for both the intentional and incidental groups. Ss were instructed to read and search the stories for errors "as if they were proofreaders." These errors were of the general typographical variety: obvious misspellings, run-on words, duplicated letters, letter reversals. and inappropriate symbols. There were 20 errors in each paragraph. and $S s$ were to read and circle as many of these errors as possible. Ss were given $2 \mathrm{~min}$ to read each paragraph and circle errors.

The material that was tested for retention under both intentional and incidental learning conditions consisted of specific examples of various categories of items presented in the stories. A total of 36 exampies of these categories (seven categories in each story) were dispersed by having nine present in each paragraph. Several categories of the "drug" story were: numbers, colors. animals, and parts of the body. For the "western town" story these included: tools and materials. geographical locations, foods, and businesses.

Related to one of the experimental manipulations. half of the Ss were tested under an incidental learning condition. Specifically. no mention was made of any test of specific content of the stories. The instructions given to these Ss were as follows: "In the following task your job will be to find as many" errors as possible in the paragraphs of a story which you will read. Since you will be given only 2 minutes per paragraph. it is important that you work quickly but accurately. When you find an error in the paragraph. circle it with your pencil. When you finish the paragraph, put your pencil down and wait. Do not go on to the next page until you are told to do so. Those errors are of a typographical nature: misspellings. run-on words. duplicated letters, etc. It is important that you work as accurately as possible."

Thus. following the reading of both stories. Ss were given tests of learning. Initially presented was a grid having the seven categories of elements listed. Instructions indicated to list as many of the examples of these categories as appeared in the story. Ss were given a maximum of $6 \mathrm{~min}$ for this (recall measure of incidental learning). Following this. Ss were presented with a listing of the seven categories of elements. under each of which were 15 examples. Among these were the actual ones that had appeared in the story. For each category. the $\mathrm{S}$ was instructed how many had actually appeared (either five or six) and was told to circle only that number for his choices, but no more. Six minutes maximum were also allotted for the test (recognition measure of incidental learning). It should be noted that these tests were subsequent to the reading of both stories (eight paragraphs). Each story was presented individualiy with a description of the cover task.

It should be noted also that none of the incidental stimul were involved with any type of error. This insured that the incidental nature of the examples would not be contaminated by association with the presence of errors. Also, the last sentence of each paragraph was free of examples to insure that differential reading speeds would not determine the number of examples encountered.

The remaining half of the $S s$ were run under an intentional learning condition. The instructions to these $S$ s differed from those to the incidental group with the addition of the following statement: "In addition to how well you can find errors in the story. you will also be tested for how well you can remember particular facts about the story. Specifically, you will be asked to supply examples of the following categories of things which you encounter in your reading: (cutegories appropriate to each 
story). The examples of these categories are dispersed throughout the story."

In order to facilitate this intentional learning. a listing of the seven categories was given at the top of each of the four paragraphs for each story. Identical testing and time parameters used for the incidental group were employed.

In regard to the other experimental manipulation. Ss in both the incidental and intentional groups received both a high- and low-meaningful story. The low-meaningful version of each story was achieved through randomization of the seven sentences in each paragraph (with the exception of Sentence 7) and the randomization of words within each sentence. The high-meaningful story was a normal narrative passage. Because of the nature of the low-meaningful material and its inappropriateness as the first story. each $S$ always received the low-meaningful story' second, although this "nested" a practice effect within one level of meaningfulness. Both stories occurred equally of ten as the first (high meaningful) to be presented.

For each $S$ three scores were derived: the number of errors correctly found in each paragraph (cover task performance. total possible score of 20) and both a recall and recognition score of correctly remembered examples of the categories in each paragraph (total possible score of 9). A 2 by 2 by 4 analy sis of variance (learning condition: incidental vs intentional by task meaningfulness by paragraphs) with repeated measures on the last two factors was performed on each of these three scores.

\section{RESULTS}

Presented in Table 1 are the mean performance levels of the two measures of learning (recall and recognition) by type of learning condition (incidental vs intentional) and level of task meaningfulness averaged across paragraphs. Table I presents the performance levels of the same variables by learning condition and paragraph of the story. The $F$ tests associated with these means were as follows: for recall. main effects for learning condition $(\mathrm{F}=21.65 . \mathrm{df}=1 / 134, \mathrm{p}<.001)$. task meaningfulness $(F=10.01$. $d f=1 / 134 . p<01)$. and paragraphs $(F=12.18 . \mathrm{df}=3 / 402 . \mathrm{p}<.001)$. There were no significant interactions present between any of the factors. For the effect of paragraphs, comparisons between means (Tukey procedure) indicated the lack of significant differences $(p<.05)$ in recall scores between Paragraphs 1 and 3.1 and 4 . and 2 and 3 .

A similar pattern of statistical findings was obtained for recognition: main effects for learning condition $(F=48.13, \mathrm{df}=1 / 134 . \mathrm{p}<.001)$. task meaningfulness $(F=15.21 . \quad \mathrm{df}=1 / 134 . \quad \mathrm{p}<.001)$, and paragraphs

Table 1

Mean Performance Levels for Incidental and Intentional Learning (Recall and Recognition) by Levels of Task Meaningfulness

Task Meaningfulness

\begin{tabular}{lccc} 
& \multicolumn{2}{c}{ Task Meaningfulness } & Mean \\
\cline { 2 - 3 } & Low & High & \\
Recall & Incidental & Learning & \\
Recognition & 1.26 & 1.48 & 1.37 \\
& 5.15 & 5.45 & 5.30 \\
Recall & Intentional & Learning & \\
Recognition & 3.01 & 3.41 & 3.21 \\
\hline
\end{tabular}

Table 2

Mean Performance Levels for Incidental and Intentional Learning (Recall and Recognition) by Paragraphs

\begin{tabular}{lllll}
\hline & \multicolumn{4}{c}{ Paragraph } \\
\cline { 3 - 5 } & 1 & 2 & 3 & 4 \\
\hline $\begin{array}{l}\text { Incidental Learning } \\
\quad \text { Recall }\end{array}$ & 1.41 & 1.11 & 1.21 & 1.75 \\
$\quad$ Recognition & 5.53 & 5.00 & 4.75 & 5.92 \\
$\quad$ & & & \\
$\quad$ Intentional Learning & & & & \\
$\quad$ Recall & 3.42 & 2.80 & 3.02 & 3.60 \\
$\quad$ Recognition & 7.51 & 6.81 & .7 .23 & 7.89 \\
\hline
\end{tabular}

$(F=42.64, d f=3 / 402, p<.001)$. Again no significant interactions were present. Comparisons between paragraphs indicated that there were no significant differences between Paragraphs 1 and 4 or 2 and 3 .

A similar statistical design was applied to cover task performance, i.e., the number of errors correctly found in each paragraph. The $F$ tests obtained were: learning condition $(\mathrm{F}=5.25, \mathrm{df}=1 / 134, \mathrm{p}<.05)$, paragraphs $(\mathrm{F}=48.42, \mathrm{df}=3 / 402, \mathrm{p}<.001)$, and meaningfulness $(F=54.23 . d f=1 / 134, p<.001)$. The means associated with levels of meaningfulness were: low meaningfuiness $=12.56$, high meaningfulness $=15.18$. Table 3 presents cover task performance level by learning condition and paragraph of the story to fully explicate the nature of the phenomena under investigation. For both learning conditions, only Paragraphs 2 and 3 were not significantly different from each other in level of cover task performance. It should also be noted that no significant interactions between factors were obtained.

\section{DISCUSSION}

The results allow several points of some consequence to be made concerning incidental learning. Within the context of a continuous verbal task. in which the incidental material is fairly intrinsic to the intentional task. task meaningfulness does not differentially affect intentional and incidental learning. The absence of a significant interaction of Learning Condition by Task Meaningfulness as well as any trend in the means supports this conclusion. It should be noted that, while the material was presented in connected form, only recall and recognition of disconnected items were assessed. However. the consistent effect of meanngfulness across learning conditions does indicate that both intentional and incidental learning of such items are influenced by the context in which these stimuli are presented. Given the qualification. it is nonetheless noteworthy that this finding contrasts with that of Postman and Adams (1960). who found a greater effect of meaningful sequence for intentional as opposed to incidental learning. although that study considered several levels of meaningfulness. whereas the present investigation considered two somewhat extreme ones. It this. then. suggests some possible curvilinear relationship 
Table 3

Mean Cover Task Performance Level by Learning Condition and Paragraph of the Story

\begin{tabular}{lccccc}
\hline & 1 & 2 & 3 & 4 & Mean \\
\hline $\begin{array}{l}\text { Incidental } \\
\text { Learníng }\end{array}$ & 13.78 & 15.36 & 15.37 & 14.39 & 14.72 \\
$\begin{array}{l}\text { Intentional } \\
\text { Learning }\end{array}$ & 12.12 & 14.35 & 14.10 & 11.51 & 13.02 \\
\hline
\end{tabular}

between meaningfulness and incidental learning, then further research is warranted. However, the employment of a more integrated task (i.e., the intrinsic relationship between cover task requirements and material tested for learning) may indicate that the absence of explicit intention to learn does not necessarily preclude some response by the learner to increased task meaningfulness. This response may indeed be relatively equal in magnitude to that of the intentional learner, an issue still of concern to researchers in this area.

A further implication of this finding concerns the reiationship between intentional and incidental learning. The presence of an effect of stimulus meaningfulness upon both measures of incidental and intentional learning lends support to the generalization that both types of performance may be affected similarly by important task characteristics. Any observed discrepancy between levels of incidental and intentional performance, therefore, may be attributable to the presence or absence of some factor that determines the degree of learning. For example, the argument that incidental learning is less intentional learning suggests that the intent of the learner defines, possibly, the degree of attention given to material to be learned.

Within the present set of data, for example, there appears to be some support for the thesis that incidental learning is influenced by the degree of attentional processing given to the more "irrelevant" (as defined by the task) stimuli. This is found in an inspection of the shifts in performance of both the cover task and incidental learning measures under both learning conditions (Tables 2 and 3 ). There appears to be essentially the same pattern in shifts in performance under both learning conditions: an initial emphasis upon both types of performance (Paragraph 1), more attention given to cover task performance intermediate in the task as the performance approaches asymptotic level (Paragraphs 2 and 3), and a final emphasis upon learning at the expense of cover task performance (Paragraph 4). It is believed that this "emphasis" is primarily translated through the intent of the learner. While this is somewhat of an indirect inference, the presence of an intent to learn appeared to have had two basic effects: an obvious heightening of learning the examples of the categories but a depression in cover task performance (locating errors). However, the pattern of performance across paragraphs is very similar to the condition in which an intent to learn is not present. This may argue for the fact that, in a well-integrated task, incidental learning may not indeed be so "incidental." This type of learning may be only less intentional, as defined by task instructions (presence or absence of a communicated intent to learn). Ryan's (1970) comment that incidental learning should be more accurately defined as "less intentional" learning may indeed be appropriate. Thus, the apparent reciprocal relationship between cover task performance and learning, under both the intentional and incidental conditions (a relationship noted in previous research by Tresselt \& Mayzner, 1960 and Schneider \& Kintz, 1967), may be indicative that the degree of incidental learning is a function of the intensity of attentional processing. Perhaps as a task progresses, the primary or cover task requirements become progressively less demanding, necessitating less intense attention. Indeed, even under the intentional learning condition, the Ss primary consideration was directed toward the search for typographical errors. Thus, with repeated exposure to the stimuli of the task, the Ss' attention is less restricted to just those elements necessary for adequate cover task performance and comes to be directed toward the more incidental characteristics of the material. Thus, in an ongoing task, there are apparent shifts in attention, and these shifts may be related to the degree of incidental learning experienced by an $\mathrm{S}$. It is also suggested that these shifts may result as a function of a reduced demand by the orienting or cover task with repeated exposure. With a stated intent to learn, the attention is more intensely directed toward the material. Under incidental learning conditions, less learning is experienced as a function of the intensity with which the material is attended. Under either condition, however, degree of attentional processing, as evidenced by the similar pattern in performance with repeated exposure to each story, may be a most important determinant of learning.

Coupled with the finding of similar systematic changes in performance over time in both intentional and incidental learning, as well as the absence of an interactive effect between intent and meaningfulness, the present study may lend support to the argument that incidental learning may not be qualitatively different from intentional learning. Perhaps the present study contributes somewhat to a firmer theoretical position. Clearly, more research is needed in which important task variables, such as meaningfulness, are explored for possible differential effects upon learning under intentional and incidental conditions.

More studies are also necessary in which examination of shifts in performance over time (reflecting similarities or differences in cognitive strategies associated with intentional and incidental learning) is conducted. The present study offers one contribution to this continuing theoretical delineation of incidental learning.

\section{REFERENCES}

DuCette, J. P., \& Wolk, S. Attentional processes in incidental 
learning of connected material. Paper presented at the Eastern Psychological Association meeting. Washington. D.C. May 1973.

Eagle. M.. \& Leiter. E. Recall and recognition in intentional and incidental learning Journal of Experimental Psychology. 1964. 68. 58-63

Gleitman. H.. \& Gillett. E. The effect of intention upon learning. Journal of General Psychology, 1957, 57. 137-149.

Kaswan, J. Association of nonsense-figures as a function of fittingness and intention to learn. American Journal of Psychology, 1957. 70. 447-450.

Kessler. C. C.. \& Loyd. G. O. Comparison of incidental and intentional learning of meaningful material in an educational setting. Proceedings of the 78th Annual Convention of the American Psychological Association. 1970.

McLaughlin. B. "Intentional" and "incidental" learning in human subjects: The role of instructions to learn and motivation. Psvchological Bulletin, 1965, 63, 359-376.

Mechanic. A. The distribution of recalled items in simultaneous intentional and incidental learning. Journal of Experimental Psychology. 1962.64. 593-600.

Postman, L.. \& Adams. P. A. Studies in incidental learning: VIII.
The effects of contextual determination. Journal of Experimental Psychology. 1960. 59. 153-164.

Postman. L., Adams, P. A., \& Phillips, I. W. Studies in incidental learning: II. The effects of association value and of method of testing. Journal of Experimental Psychology, 1955. 49. 1.10.

Ryan, T. A. Intentional behavior: An approach to human motivation. New York: Ronald. 1970.

Schneider, F. W. \& Kintz, B. L. An analysis of the incidental-intentional learning dichotomy: Journal of Experimental Psychology, 1967.73.85-90

Tresselt. M. E.. \& Mayzner, M. S. A study of incidental learning. Journal of Psychology, 1960, 50, 339-347.

Wolk, S.. \& DuCette. J. P. Intentional performance and incidental learning as a function of personality and task dimensions. Journal of Personality \& Social Psychology, 1973. in press.

(Received for publication January 31. 1973: revision received April 1, 1973: second revision accepted May 31, 1973.) 